\title{
Redefining smoking relapse as recovered social identity - secondary qualitative analysis of relapse narratives
}

Running Head: Smoking relapse as recovered social identity

Dr Caitlin Notley (corresponding author). Senior Lecturer in Mental Health and UK Society for the Study of Addiction Research Fellow. Norwich Medical School, Norwich Research Park, University of East Anglia, Norwich. UK. Phone: 01603 591275. E mail: c.notley@uea.ac.uk orcid.org/0000-0003-0876-3304 .Twitter: @ AddictionUEA

Rory Collins. Norwich Medical School, Norwich Research Park, University of East Anglia, Norwich. UK.

\begin{abstract}
Although many people in the general population manage to quit smoking, relapse is common. Theory underpinning the determinants of smoking relapse is under-developed. This article aims to specify theoretical insight into the process of relapse to smoking, to underpin effective intervention development. Secondary qualitative analysis of extended narratives of smoking relapse $(n=23)$ were inductively coded within our conceptual framework of a socially situated narrative theoretical approach to identity. Smoking relapse is conceptualised as a situated rational response to a 'disruption' in individual narrative identity formation, and an attempt to recover a lost social identity. Emotional reactions to relapse, such as pleasure, but also guilt and shame, support this assertion by demonstrating the ambivalence of reengaging in a behaviour that is situated and rational in terms of individual identity formation, yet ostracised and stigmatised by wider culture.
\end{abstract}

Article word count: 3,982

Key words: tobacco smoking relapse, social identity, secondary qualitative analysis 


\section{Redefining smoking relapse as recovered social identity - a qualitative analysis of relapse narratives}

\section{Introduction}

Smoking cessation is the primary modifiable health behaviour that will have the greatest impact on mortality (Pirie, 2013). Many smokers are able to initially quit (CDC, 2017), and UK smoking prevalence is at an all-time low (STA, 2017 \& ASH, 2017). Nonetheless most quit attempts ultimately result in relapse to smoking. Approximately $75 \%$ of quit attempts are not maintained beyond four weeks (Ferguson et al, 2005). Both short ( Piasecki, 2006), and long term relapse following abstinence is common (Hughes et al, 2008). Most smokers will experience multiple relapses before achieving abstinence ( Chaiton et al, 2016).

Theoretical understanding of smoking relapse is underdeveloped. Theorising has primarily been psychological (Brandon et al, 2007), assuming individual level deficits in functioning; inability to resist physical urges, vulnerability to social cues to smoking; or maladaptive motivational drives (EMCDDA, 2017 \& Baumeister, 2017).

There are no effective approaches to preventing smoking relapse (Hayek et al, 2013), suggesting a need for theory development underlying future interventions. Relapse prevention theory, (Marlatt \& Donovan, 2007), has provided a theoretical basis for interventions. Central to the model is a taxonomy of risk factors precipitating relapse. Although risk factors are both individual and social, the model takes a primarily individualistic stance. The abstinence violation effect (AVE) suggests that following a cue driven initial lapse to smoking (a 'violation' of smoking abstinence), the individual's negative emotional response (Strong et al, 2011) and the causes to which they attribute the 
lapse (Shiffman, 1996), will result in breakdown of willpower, culminating in full smoking relapse (Curry et al, 1987). This effect is well evidenced (Kirchner et al, 2012 \& Shiffman et al 1997) and replicated using 'real time' feedback from participants (Shiffman et al 1997 Shiffman, 2005).

Although the AVE gives one potential explanation for the move from an initial smoking lapse to relapse, it does not provide satisfactory explanation for the underlying mechanism. Social and situational factors are recognised as important predictors of relapse (Powell et al, 2010 \& Hawkins et al, 2010), but theory has so far positioned these factors as cues as opposed to inherent explanations. The dominant model of relapse utilised within smoking cessation treatment services is the Transtheoretical Model (Prochaska et al, 1982 \& 1992). This is an integrative, biopsychosocial model, conceptualising change as a process of 'intentional' behaviour change. This model has been extremely influential, applied to smoking cessation (DiClemente et al, 1991), although not to smoking relapse prevention.

\section{Social Identity of a 'smoker'}

In this article, we define identity is a relatively stable concept, a cohesive narrative, yet simultaneously fluid and shifting, continually subject to influence at multiple levels, and idiosyncratic within certain circumstances. Identity, at least partly, is discursively produced, continually reformulated by the negotiated understanding of selfhood shared through interaction via language. Smoker identity, then, is a particular version of social identity, similar to the integrative theory of identity (Schwartz et al 2011). 
Symbolic interactionism (Blumer, 1969; Serpe \& Stryker, 2011), theorises language as symbolic information exchange, via communication. Ideas about selfhood inform individual identity as they are negotiated and rehearsed between individual actors, at a micro level in interactions, at a meso level through cultural or sub-cultural influences, and a macro level through societal influences, including discourse circulating in the language available to individuals. We interpret symbolic interactionism as extending beyond language to also encompass the exchange of 'objects'. The cigarette is a symbolic object central to the exchange of identity relevant social cues and the embodiment of the identity as a smoker.

Cigarette smoking initiation occurs as the exchange of a symbolic object in a micro-social context. The social environment and close personal relationships are major influences on first use of tobacco (Afanador et al, 2014), and most early cigarette smoking occurs in a social context supportive of smoking norms (Amos \& Hastings, 2009). Through interaction, individuals develop a smoker self-concept (Hertel \& Mermelstein, 2012), and learn, socially, to become a 'smoker' (Hughes, 2003). With repeated practice, smoking becomes habituated a ritualised social practice embodying significant meaning in defining and cementing group membership. The individual, in time, becomes a 'smoker', and is defined by others as such. Thus smoking becomes integral to identity: physically, through addiction to nicotine, psychologically through craving repeated behavioural actions and the ritual of smoking, and socially, as the individual comes to identify as a 'smoker'. Crucially, the smoker identity is not fixed, but rather uniquely experienced and interpreted by individuals within specific circumstances. 


\section{Social and cultural smoker identity shifts}

Culturally, smoking has experienced a shift in discursive construction over less than a generation. In 1950 in the UK approximately $80 \%$ of men aged 35-59 smoked, and $40 \%$ of women (Peto et al, 2000), compared to $15.8 \%$ of the UK general adult population in 2017 (STS, 2017). Smoking may now be considered de-normalised. In recent years the UK has introduced smoke free public places (Smoke Free Regulations, 2017), hidden point of sales displays (2012) (ASH, 2013), and standardised packaging (2015). Political and cultural norms have shifted so that smoking has moved from the public to the private social domain. Smoking is no longer a majority behaviour, and this looks set to continue - the recent UK Tobacco control plan for England sets an ambitious target to reduce smoking prevalence to less than $12 \%$ by $2022(\mathrm{DoH}, 2017)$. The cigarette as object has shifted as an acceptable means of cementing social ties, to being morally demonised (Butler, 1993).

\section{Narrative Smoker identity}

Identity can be conceptualised as a 'thread', or narrative, an unfolding project. Within identity literature, critical illness has been theorised as 'disconnect', an 'interruption' to the thread of individual identity (Goffman, 1986). Similarly, recent cultural shifts in positioning on cigarette use are interruptions to the continuity of the smoker identity. Once experienced as culturally normative, over time shifts in societal views towards tobacco smoking may contribute to an 'identity crisis', such that smokers come to feel ostracised within increasingly circulated discourses of smoking as unacceptable or incompatible with other aspects of identity (parent, etc). Thus the cultural narrative of identity is destabilised. Individual attempts to quit smoking, represent attempts to reconfigure a new identity. 'Disruptions', meaning challenges to new identity formation, which may include triggers to 
smoking, must either be overcome and incorporated into a new abstinent identity, or cannot be reconciled, resulting in potential relapse to smoking.

However, loss or change to the smoker identity following a quit attempt is also reconfigured through societal expectations and moral judgements. So loss of the smoker identity may mean giving up previous social groups or inhabiting different social spaces, yet simultaneously gaining a 'normative' identity as a non-smoker (Butler, 1993).

It has been suggested that, on a basic level, seeing or referring to oneself as a 'smoker' or 'exsmoker' impacts on relapse (Tombor, 2015), and transitioning towards seeing oneself as a 'non-smoker' may be important for long term abstinence (Vangeli \&West, 2012; Vangeli et al, 2010). Exploratory analysis (Notley, 2016) suggested the potential utility of smoking relapse conceptualised as restoration of the narrative of individual identity - recovering a previously held smoker identity. The analysis presented here aims to extends this theoretical treatment of smoking relapse.

\section{Methods}

Secondary analysis of qualitative data drawn from a process evaluation study of the Sharpish randomised controlled trial (Heaton, 2005; Irwin \& Winterton, 2011) . Qualitative secondary data analysis (QSA) uses previously collected qualitative data to answer new research questions (Heaton, 2005; Irwin \& Winterton, 2011). We gathered narrative extracts of smoking relapse descriptions, from which the analysis presented in his paper arose. Uur analysis for this paper focused on 'prioritising a concept or issue that was present in the original data but 
was not the analytical focus at that time'. Specifically, we utilise data collected for a specific purpose for wider theory development.

\section{Contextual information - The Sharpish Trial}

The trial (ISRCTN 36980856) (Maskrey et al, 2015) recruited short-term quitters (quit smoking for 4 weeks) from UK NHS stop smoking clinics. 1407 carbon monoxide (CO) validated quitters were randomised to receive either self help booklets or a single control leaflet. The primary outcome was prolonged, CO-verified abstinence. Qualitative data were collected at 12 month follow up.

\section{Participants and procedure}

The qualitative process evaluation purposefully recruited 43 participants who had and had not relapsed from both trial arms (Notley et al, 2017). All participants gave written informed consent. In-depth interviews followed a topic guide asking participants to describe their history of smoking and previous quit attempts, the current quit attempt in the context of the RCT, followed by a discussion of any smoking lapses or relapse where relevant. The sample was representative of the trial population (Notley et al, 2017). A purposive sample of 23 participants have been drawn upon for this paper, selected according to the longer relapse narratives that they gave. These 'exemplar cases' best inform the theoretical concepts of narrative identity formation in smoking cessation and relapse. Clearly findings require further development and eventual testing for utility in intervention development, and thus no claims are made for representativeness nor generalisability. 
The interview guide was developed in consultation with lay representatives. Interviews were audio recorded, transcribed and fully anonymised. Ethical approval for the study was obtained from the East of England Research Ethics Committee (reference number: 11/EE/0091).

\section{Analysis}

Following a Grounded Theory approach as being most suited to the study aims of developing theory (Glaser \& Strauss, 1967), initial open coding using NVivo software was organised into higher level (axial) coding. Sequentially, targeted inductive coding of participant narratives was undertaken by the lead author, utilising a constant comparison technique (Charmaz \& Bryant, 2011) of interpretative memo writing alongside coding to check and re-check emergent analysis against the data. The second author independently inductively coded all 23 narratives. Coding was compared and combined to ensure credibility and to increase confidence in the analytical interpretations.

Secondary analysis focused on examining particular displays of identity within the data according to the conceptual framework of the smoker identity set out. This approach is in accordance to Charmaz's constructivist version of grounded theory (Charmaz \& Bryant, 2011), in which epistemological assumptions, and particular theoretical perspectives, are explicitly acknowledged as deductively imposed structures alongside the simultaneous inductive process of data analysis.

\section{$\underline{\text { Results }}$}




\section{Smoking cessation as integral to individual narratives of identity - experiencing cessation as 'loss'}

Cessation was challenging, for a multitude of reasons (e.g. health related, pressures from others, increasing perceived cultural unacceptability of smoking). Expressed reasons for cessation may meet the situated identity needs of individuals, at an intersection in their narrative identity formation.

However, some individuals experience smoking cessation simultaneously as a positive health 'gain' and a social 'loss'. Removing, or burying, a previously integral part of one's social identity is difficult to adjust to:

I've found that, quite so, yes, but it wasn't, it's more of the long term, it was ended up, like I say, being a crutch (ok) it was sort of something to look forward to, something, and I realised then you know, that, um, it meant more to me than I thought (ok) so I couldn't see myself going a lot longer without having that back

0818

The 'loss' to the identity of smoking was, for this person at this moment in the narrative construction of their identity, too great, resulting in relapse.

\section{The process of relapse - retaining the smoker identity}

It was the norm to have experienced cycles of lapse, relapse and regular smoking alongside quit attempts of varying duration. Relapse suggests the self-identity as smoker is 'retained' or 'residual' (Kirchner et al, 2012). This was demonstrated multiple times: 
and um I learned then, and I've subsequently learned, that it is after about a year of not being smoking you think 'ah, I'll just have a cigarette now', 'I don't smoke' it's as simple as that (right) and within a week I was smoking again

\section{1}

Here, the participant describes allowing a brief lapse to cigarette smoking, rationalising the acceptability of this as someone who 'does not now smoke'. However, the abstinence status expressed ('I don't smoke') permits residual attraction to smoking, thus maintenance of a smoker identity that may make relapse likely. This is in comparison to the alternative identity of non-smoker, which might be expressed more concretely as a part of selfhood, rather than an action ('I am not a smoker') which may, hypothetically, conversely be protective against smoking lapse.

For others, relapse was described positively, socially, in regaining the previous smoker identity. However, at the point of relapse, individuals simultaneously experienced guilt, shame or embarrassment:

obviously, cos I was upset about what my son had done but at the same time I was absolutely gutted that I'd sort of like done so well, and come so far, and this one incident, I mean I only had half a cigarette but that was enough to sort of like, get me hooked again

0754 
The participant emotionally expresses guilt and remorse at what she sees as failure, as measured against societal expectations to quit smoking. This reveals the moral dimension to smoking, drawing on cultural norms of smoking behaviour in wider society. In this context, relapse to smoking precipitates guilt, which is conceivably absorbed within the individuals social identity in such a way that they come to see themselves as weak, a failure.

Interestingly, the participant demonstrates that these negative feelings are not fully integrated, as simultaneously she justifies the relapse given the immediate family situation. In this case, stressful behaviour of the woman's son precipitated the lapse, legitimising relapse as adaptive. The relapsed social identity is situated, complex and multifaceted, as the recovered social identity regained through relapse relies on smoking as a form of stress relief. Thus a line is drawn between situations in which relapse is considered reasonable, logical and justified in reaction to social conditions conducive to coping, reinforcing the social identity of the smoker.

If we conceptualise smoking relapse as recovering a lost sense of social identity, given or stated 'triggers' to relapse may be more usefully viewed as socially organised 'disruptions' to individual narrative identity formation with abstinence as a central feature, such that relapse is a response.

\section{Discourses of Addiction - It's not my fault!}

Identification with societal discourses of addiction as 'disease' enabled some participants to position returning to smoking as beyond individual control, free of blame. In the following extract, the disease discourse gives a final passive explanation that cannot be reproached: 
Pt: $\quad$ so there was no really association to it, I just decided that 'oh' I fancy one', so I had one (ok)...bad mistake

R: $\quad$ and you said that quickly led to...

Pt: $\quad$ yes, once I'd had one I was instantly hooked on it again

0728

This extract demonstrates the complex identity work at play as individuals discuss and conceptualise smoking relapse. Relapse is a rational 'treat' permissible on holiday, but also an 'unstoppable force' in the face of having tried the acceptable approach of medical assistance with preventing relapse. Finally stated is the passive position drawing on the addiction discourse to justify relapse.

\section{Discursive resistance}

For some there was resistance to accepting the relapse status:

Pt: $\quad$ it was a slippery slope, I can't even remember the first one, I might have had a puff cos my sister smokes

R: $\quad$ right ok

Pt: $\quad$ and I may have had, I think what I did, cos she's away through the winter, she works in Australia

R: $\quad$ right 
Pt: $\quad$ she comes back about April, May time, and I think that's when I had one of hers

R: $\quad y e s$, and that's your sister and you normally smoke when you see her and smoke together do you?

Pt: $\quad$ um, yes, we seem to, yes

0697

The language used here demonstrates resistance. 'I can't even remember' minimises the significance of the event. 'I might have had a puff' only partly acknowledges the actual inhalation of smoke, whilst still leaving the possibility that 'I might not have done this'. 'Cos my sister smokes' infers blame on another, denying personal responsibility, and 'we seem to, yes' begrudgingly agrees that smoking relapse occurs in the social circumstance of meeting a family member. Resistance and ambivalence suggests that 'relapse' as a state is problematic, because it clearly means different things to different people, and therefore the begrudging acceptance of the category 'relapse' masks the social situatedness of the narrative identity that was vulnerable to disruption and led to relapse in that moment.

\section{Acceptance - Recovering a lost social identity}

When describing lapse to smoking, it was common for individuals to express a sense of relief, an emotional response suggestive of regaining meaningful identity. Thus the pleasurable experience enables the individual to recapture the situated meaning of the act of smoking - recapturing the lost smoker identity:

$R: \quad$ can you remember what happened when you went back to smoking? 
Pt: $\quad$ loved it, yes

0818

But the pleasure was not always maintained:

I can remember the first cigarette was um initially was elation: 'oh good, I'm having a cigarette' and everything, and then after you get through the first? you think 'oh no, what have I done? cos I've gone through all that effort of stop smoking, and there I am, I'm back to, literally, back to square one again

0792

Initial euphoria is quickly replaced with guilt, remorse or disappointment, which are emotions clearly linked to moral discourses of smoking. Although this may motivate some to see the lapse as a one off occurrence and continue to form a narrative identity with abstinence as a central feature, for others, the sense of relief is so great, that relapse is inevitable, and the recovered social identity of oneself as a smoker is embraced despite the moral dimension creating ambivalence.

Acceptance and embracing the recovery of one's identity as a smoker, which was 'lost' during the quit attempt, was primarily described as passive. Many described an 'inevitable slide' back to smoking. For a minority, the acceptance was less passive, even overtly sought and explained as an adaptive response: 
Pt: $\quad$ um yes it was sort of slap bang, 'oh my god what am I going to do?' I was in a hell of a state, and yes (ok)...went and bought a box of cigarettes

R: $\quad$ ok, so you did that purposefully, you thought that will, you know, will make me cope and make me feel better

Pt: $\quad$ yes I did yes, yes

0779

Taking ownership of one's actions requires less justification and rhetoric than in previous examples. Passive acceptance of addiction as a disease or relapse as a response to stress clearly require greater identity 'work' in justifying the behaviour in the face of social and cultural challenge. The social identity displayed here, in contrast, is largely confessional and allows a simply constructed narrative clearly positioning oneself as a self-identified relapsed smoker.

\section{Discussion}

This paper has utilised secondary qualitative inductive analysis to provide evidence of relapse as a consequence of disrupted identity that can't be reconciled by continued abstinence.

Therefore, relapse to smoking can be theoretically understood as an individually negotiated and situated attempt, either passive or active, to 'recover' a sense of lost social identity. This may not be central for all individuals experiencing relapse, but is nonetheless an important and original theoretical hypothesis. Conceptualising relapse in this way requires biopsychosocial understanding of identity in relation to tobacco smoking, encompassing physical dependence, psychological factors, particularly motivation, but also importantly social and cultural influences that impact on a constructed narrative version of identity. The 
smoker identity has associated pleasurable emotions, yet simultaneous emotions of guilt and shame, attached to it. The smoker identity is relatively enduring over time, yet social and cultural destabilisation may lead to cessation attempts. Despite this, there is a retained smoker identity (Lawson, 1997) underpinning the process of relapse in terms of 'recovering' the identity 'lost' through abstinence. Furthermore, the 'smoker identity' is idiosyncratic, being interpreted and meaningful to individuals in their unique social contexts, impacted upon by wider cultural norms and discourses.

Smoking cessation itself can be understood as part of an individual narrative. Reasons for cessation fit the narrative at a given moment in time, giving coherence to the fluidity of identity as it shifts from 'smoker' to 'ex-smoker'. But, similarly, relapse can be understood as incorporated into the emergent constructed narrative, so if, for example, smoking is associated in the previous smoker identity as stress relief, then a stressful situation may disrupt the new identity formation, triggering relapse. In this sense the disruption of 'stress' can be used as a justification for relapse. This allows the individual to incorporate relapse as part of their ongoing unfolding identity, as being a rational response. The concept of situated rationality (Lawson, 1997) is useful here, as relapse behaviour may not be objectively viewed as 'rational', yet, through the individual lens of a socially constructed narrative identity, it becomes entirely rational.

The investment in smoking as integral to identity is strong. Individuals experience feelings of loss on cessation. Stopping smoking is difficult, with individuals often having to forcibly remove themselves from established social groups, and thus possibly experiencing a sense of isolation, of 'identity crisis' (Goffman, 1986). Individuals may move through this to develop 
new identities ('non-smoker', or 'recovered ex-smoker'). However, for many this process is too difficult, or the timing in the individual narrative is not right. In these instances, relapse to smoking can be experienced as relief, the sense of identity previously heavily invested in smoking as a symbolic representation of that identity, is 'recovered'.

However, given recent cultural denormalisation of smoking, one current issue for those relapsing is whether previous social identities remain available for rediscovery.

Contemporary legislation has changed social practices and therefore the relationship of individuals to smoking is altered, possibly creating additional ambivalence, as the previous social identity of 'smoker' may no longer be readily available. There are questions then, about the nature of rediscovered social identity for the relapsed smoker, if the social conditions have changed. Moving forward, ex-smokers may find that their options are limited, which may make a case for viable identity related alternatives, such as vaping.

The Transtheoretical model of smoking relapse (Prochaska, 1992) has practical utility, yet fails to acknowledge the underpinning concept of identity, which may influence behaviour at a non-intentional level, providing an explanation of relapse that is individually rationally situated. The advantage of the model is that it incorporates relapse as part of a cyclical process on a journey towards abstinence, allowing individuals to enter or leave the process at any point. In contrast, Marlatt and Gordons' (2007) relapse prevention model is linear, suggesting inevitability and a lack of agency. Both models accept social influence on relapse whilst foregrounding individual psychological responses as reactions, rather than a truly integrative process, to the social context. The implication of this lack of integration are that notions captured in current models, such as 'effective coping response' and 'increased self 
efficacy', are presented as fixed, stable and decontextualized states. This has limited practical application considering the fluidity of narrative identity formation, shifting over time and context, meaningfully impacting the situated positions of individuals at the point of smoking relapse.

We recognise as a limitation our secondary analysis is of data that was collected within the artificially created social confines of a research interview, where individuals construct and present a particular version of identity in response to perceived norms and interaction with a researcher. Clearly there is a need for further refinement and testing of our theoretical approach. The analysis presented here suggests that identity needs to specifically be understood as situated and temporally meaningful to individuals in order to understand the meaning of relapse in ongoing narrative identity formation. Understanding this is a minimal requirement prior to supporting potential change. If an effective relapse prevention intervention incorporating situated narrative identity formation can be developed, then implications are significant. Even a modest impact to preventing smoking relapse would have significant net health and economic gains, through prevention of smoking related morbidity and mortality.

\section{Acknowledgements:}

\section{Declaration of Interest \& Funding:}

This work was supported by fellowship funding from the UK Society for the Study of Addiction. The SHARPISH trial was funded by the NIHR Health Technology Assessment programme (Project 09/91/36). Visit the HTA programme website for more details www.hta.ac.uk/link to project page. The views and opinions expressed therein are those of the authors and do not necessarily reflect those of the Department of Health. 
$\mathrm{CN}$ is a funded Fellow of the Society for the Study Addiction.

No conflicts of interest. We attest that we have herein disclosed any and all financial or other relationships that could be construed as a conflict of interest.

\section{Clinical trial registration:}

In this paper, we utilise secondary qualitative analysis of process evaluation data collected in the UK as part of an NIHR HTA funded randomised controlled trial of a self-help smoking relapse prevention intervention (ISRCTN 36980856).

We thank service user representatives for their invaluable feedback in developing analysis, and study participants involved in the qualitative data collection. We acknowledge the support of the NIHR, through the Primary Care Research Network. Smokefree Norfolk assisted with identifying and recruiting participants to the process evaluation study and we are grateful for their support. 


\section{References:}

Afanador L del PC, Radi DSS, Pinto LEV, Pinzón CEP, Carreño MFC. (2014) Sociocultural Determinants of Tobacco Smoking Initiation among University Students in Bucaramanga, Colombia,. Int J Prev Med. 5(9):1106-12.

Action on Smoking and Health (ASH (2013) ASH Briefing on Tobacco displays at the point of sale. Available from: http://smokefreeaction.org.uk/wp-

content/uploads/2017/06/ASH_701.pdf

Action on Smoking and Health (ASH). (2017) Smoking Statistics: Who Smokes and How Much | Action on Smoking and Health [Internet]. [cited 2017 Jul 24]. Available from: http://ash.org.uk/information-and-resources/fact-sheets/smoking-statistics-who-smokes-andhow-much/

Amos, A \& Hastings, G (2009) A Review of Young People and Smoking in England (2009). Available from: http://phrc.lshtm.ac.uk/papers/PHRC_A7-08_Final_Report.pdf

Baumeister RF. (2017) Addiction, cigarette smoking, and voluntary control of action: Do cigarette smokers lose their free will? Addict Behav Rep. 2017 Jun;5:67-84.

Blumer H. (1969) Symbolic interactionism; perspective and method. Englewood Cliffs, N.J.: Prentice-Hall.

Brandon TH, Vidrine JI, Litvin EB. (2007) Relapse and relapse prevention. Annu Rev Clin Psychol.;3:257-84.

Butler K. (1993) The Moral Status of Smoking. Soc Theory Pract. 19(1):1-26.

Centers for Disease Control and Prevention Health (CDC). (2017) Smoking and Tobacco Use; Fact Sheet; Smoking Cessation [Internet]. Smoking and Tobacco Use. [cited 2017 Jul 24]. Available from: http://www.cdc.gov/tobacco/data_statistics/fact_sheets/quitting/

Chaiton M, Diemert L, Cohen JE, Bondy SJ, Selby P, Philipneri A, et al. (2016) Estimating the number of quit attempts it takes to quit smoking successfully in a longitudinal cohort of smokers. BMJ Open. Jun 1;6(6):e011045.

Charmaz, C \& Bryant, A (2011) Constructing Grounded Theory Analyses in Silverman, D (Ed) 'Qualitative Research' $3^{\text {rd }}$ Edition. London: Sage Publications.

Curry, S, Marlatt, G.A \& Gordon, J.R. (1987) Abstinence Violation Effect: Validation of an Attributional Construct With Smoking Cessation. Journal of Consulting and Clinical Psychology. 55:2, 145-149.

Department of Health (DoH) (2017) Towards a smoke-free generation: tobacco control plan for England. Available from: https://www.gov.uk/government/publications/towards-a-smokefree-generation-tobacco-control-plan-for-england 
DiClemente CC, Prochaska JO, Fairhurst SK, Velicer WF, Velasquez MM, Rossi JS. (1991) The process of smoking cessation: an analysis of precontemplation, contemplation, and preparation stages of change. J Consult Clin Psychol. 59(2):295-304.

EMCDDA (2017) Models of addiction. Available from:

http://www.emcdda.europa.eu/publications/insights/models-addiction

Ferguson J, Bauld L, Chesterman J, Judge K. (2005) The English smoking treatment services: one-year outcomes. Addiction. 2005 Apr;100 Suppl 2:59-69.

Glaser B, Strauss A. (1967) The discovery of grounded theory: strategies for qualitative research. Chicago: Aldin Pub. Co.

Goffman E. (1986) Stigma: Notes on the Management of Spoiled Identity. New York: Touchstone books.

Heaton, J (2005). Reworking Qualitative Data. London: Sage Publications.

Hajek P, Stead LF, West R, Jarvis M, Hartmann-Boyce J, Lancaster T. (2013) Relapse prevention interventions for smoking cessation. Cochrane Database Syst Rev. Aug 20;(8):CD003999.

Hawkins J, Hollingworth W, Campbell R. (2010) Long-term smoking relapse: a study using the British household panel survey. Nicotine Tob Res12(12):1228-35.

Hertel AW, Mermelstein RJ. (2012) Smoker identity and smoking escalation among adolescents. Health Psychol 31(4):467-75.

Hughes J. (2003) Learning to Smoke: Tobacco Use in the West. University of Chicago Press

Hughes JR, Peters EN, Naud S. (2008) Relapse to Smoking After 1 Year of Abstinence: A Meta-analysis. Addict Behav. Dec;33(12):1516-20.

Irwin, S \& Winterton, M (2011) Debates in Qualitative Secondary Analysis: Critical Reflections A Timescapes Working Paper. (Timescapes Working Paper Series No.4). Available from: http://forscenter.ch/wp-content/uploads/2013/11/wp4-march-2011.pdf

Kirchner TR, Shiffman S, Wileyto EP. (2012) Relapse dynamics during smoking cessation: recurrent abstinence violation effects and lapse-relapse progression. J Abnorm Psychol. 121(1):187-97.

Lawson T. (1997) Situated rationality. J Econ Methodol. 4(1):101-25.

Marlatt, G.A. \& Donovan, D.M. (2007) Relapse Prevention: Maintenance Strategies in the Treatment of Addictive Behaviors. Second Edition. London: Guilford Press.

Maskrey, V., Blyth, A., Brown, T. J., Barton, G. R., Notley, C., Aveyard, P., Holland, R., Bachmann, M. O., Sutton, S., Leonardi-Bee, Jo., Brandon, T. H., and Song, F. (2015) Self-help educational booklets for the prevention of smoking relapse following smoking cessation treatment: a randomized controlled trial. Addiction, 110: 2006-2014. doi: $10.1111 /$ add.13080.

Notley C. (2016) Conceptualising smoking relapse as recovered social identity: Secondary analysis of UK qualitative data from a trial of smoking relapse prevention. (conference presentation at Society for Research on Nicotine and Tobacco (USA). 
Notley C, Blyth A, Maskrey V, Karavadra B, Brown T, Holland R, et al. (2017)) Self help materials for smoking relapse prevention: A process evaluation of the SHARPISH randomised controlled trial. J Public Health Available from:

https://ueaeprints.uea.ac.uk/62154/

Peto R, Darby S, Deo H, Silcocks P, Whitley E, Doll R. (2000) Smoking, smoking cessation, and lung cancer in the UK since 1950: combination of national statistics with two casecontrol studies. BMJ. 321(7257):323-9.

Piasecki TM. (2006 )Relapse to smoking. Clin Psychol Rev. Mar;26(2):196-215.

Pirie K, Peto R, Reeves GK, Green J, Beral V, (2013) Million Women Study Collaborators. The 21st century hazards of smoking and benefits of stopping: a prospective study of one million women in the UK. Lancet Jan 12;381(9861):133-41.

Powell J, Dawkins L, West R, Powell J, Pickering A. (2010) Relapse to smoking during unaided cessation: clinical, cognitive and motivational predictors. Psychopharmacology (Berl). 2010 212(4):537-49.

Prochaska JO, DiClemente CC. (1983) Stages and processes of self-change of smoking: toward an integrative model of change. J Consult Clin Psychol. 51(3):390-5.

Prochaska JO, DiClemente CC, Norcross JC. (1992) In search of how people change. Applications to addictive behaviors. Am Psychol. 47(9):1102-14.

Schwartz, S, Luckx, K \& Vignoles, V.L (Eds) (2011) Handbook of Identity Theory and Research. New York: Springer.

Smoking Toolkit Study (STS) (2017) Latest Statistics - Smoking In England [Internet]. [cited 2017 Jul 24]. Available from: http://www.smokinginengland.info/latest-statistics/

Serpe, R \& Stryker, S. (2011). The Symbolic Interactionist Perspective and Identity Theory. 10.1007/978-1-4419-7988-9_10. In Schwartz, S.J. Luyckx, K., \& Vignoles, V. L. (Eds.) Handbook of identity theory and research 225-248. doi: 10.1007/978-1-4419-7988-9_25.

Shiffman S. (2005) Dynamic influences on smoking relapse process. J Pers. 2005 73(6):1715-48.

Shiffman S, Hickcox M, Paty JA, Gnys M, Kassel JD, Richards TJ.(1996) Progression from a smoking lapse to relapse: prediction from abstinence violation effects, nicotine dependence, and lapse characteristics. J Consult Clin Psychol. Oct;64(5):993-1002.

Shiffman S, Hickcox M, Paty JA, Gnys M, Kassel JD, Richards TJ. (1997) The Abstinence Violation Effect Following Smoking Lapses and Temptations. Cogn Ther Res. 21(5):497523.

Strong DR, Evatt DP, Greenberg BD, Leventhal AM, Haber S, Abrams D, et al. (2011)

Positive Reactions to Tobacco Predict Relapse After Cessation. J Abnorm Psychol.

Nov;120(4):999-1005.

The Smoke Free Regulations (2017) Available from:

https://www.smokefreeengland.co.uk/thefacts/the-regulations/ 
The Standardised Packaging of Tobacco Products Regulations (2015)

https://www.legislation.gov.uk/uksi/2015/829/contents/made

Tombor, I., Shahab, L., Brown, J., Notley, C., \& West, R. (2015). Does non-smoker identity following quitting predict long-term abstinence? Evidence from a population survey in England. Addictive Behaviors, 45, 99-103. http://doi.org/10.1016/j.addbeh.2015.01.026

Vangeli E, West R. (2012) Transition towards a "non-smoker" identity following smoking cessation: An interpretative phenomenological analysis. Br J Health Psychol. 17(1):171-84.

Vangeli E, Stapleton J, West R. (2010) Residual attraction to smoking and smoker identity following smoking cessation. Nicotine Tob Res 12(8):865-9. 